\title{
ELETROTERAPIA NO PROCESSO DE REPARAÇÃO DA SUPERFÍCIE ARTICULAR DE COELHOS
}

\author{
ELECTROTHERAPY ON THE HEALING PROCESS IN THE ARTICULAR SURFACE \\ OF RABBITS
}

\author{
Tayse Domingues de Souza ${ }^{2}$ Ricardo Junqueira Del Carlo ${ }^{3}$ \\ Marlene Isabel Vargas Viloria ${ }^{4}$
}

\section{RESUMO}

Os efeitos da eletroestimulação pós-operatória no processo de reparação de falhas osteocondrais induzidas no sulco troclear de 36 coelhos adultos foram avaliados histologicamente. $O$ grupo controle apresentou tecido de granulação típico, com duas semanas de pós-operatório (PO); cartilagem hialina foi observada após quatro e sete semanas de PO e a reconstituição do osso subcondral excisado limitou-se ao fundo da falha, até sete semanas de PO. No grupo I (eletroestimulado diariamente), o tecido de granulação apresentou vascularização exuberante após duas semanas de PO; após sete semanas de PO, o tecido de reparação permaneceu indiferenciado superficialmente, com formação de novo osso subcondral até o nível da junção osteocondral preexistente. No grupo II (eletroestimulado em dias alternados), os animais responderam de duas maneiras: através da reparação com cartilagem hialina e osteogênese reduzida, semelhante ao grupo controle; ou pela formação de tecido indiferenciado $e$ osteogênese intensa, como no grupo I. Concluiu-se que a eletroestimulação pós-operatória realizada impediu a diferenciação tecidual em cartilagem hialina em coelhos. Por outro lado, a ossificação endocondral foi acelerada, observandose reconstituição do osso subcondral até o nível da junção osteocondral preexistente nos animais tratados com este método. Em face da importância do osso subcondral na manutenção da integridade do tecido de reparação, a eletroestimulação é benéfica na fase inicial (quatro semanas) da reparação de falhas osteocondrais.

Palavras-chave: cartilagem articular, fisioterapia, reparação óssea.

\section{SUMMARY}

The effects of postooperative electrotherapy in the repair of full-thickness osteochondral defects in the troclear

\begin{abstract}
groove of 36 adult rabbits were evaluated histologically. In the control group, granulation tissue was present two weeks postoperatively (PO); hyaline cartilage was observed at four and at seven weeks $P O$; subchondral bone regeneration was limited to the deeper portions of the defects at seven weeks PO. In group I (stimulated daily), granulation tissue presented abundant vascularization at two weeks $P O$ and the repair tissue remained undifferentiated superficially, with formation of new subchondral bone up to the level of the original osteochondral junction, at seven weeks PO. The animals in group II (stimulated every other day), responded in two ways: through repair with hyaline cartilage, with reduced osteogenesis, similar to control group; or undifferentiated tissue, with an intense osteogenesis, as in group I. The postoperative electrical stimulation inhibited the tissue differentiation into hialine cartilage. On the other hand, endochondral ossification was accelerated, with complete regeneration of subchondral bone, in treated animals. In view of the importance of the subchondral bone for the integrity of the repair tissue, electrical stimulation is benefic in the initial fase (four weeks) of osteochondral defects repair.
\end{abstract}

Key words: articular cartilage, physiotherapy, bone repair.

\section{INTRODUÇÃO}

As patologias que envolvem lesão da cartilagem articular estão freqüentemente associadas a prognóstico reservado, devido à dificuldade de plena regeneração da cartilagem hialina e à possível evolução para doença articular degenerativa, resultando em hipofunção da articulação e comprometimento do desempenho e bem estar do animal. Cães de raças de crescimento rápido,

\footnotetext{
${ }^{1}$ Apoio financeiro da FAPEMIG.

${ }^{2}$ Médico Veterinário, Mestre, Professor do Curso de Medicina Veterinária do Centro Superior de Vila Velha, Universidade de Vila Velha, ES.

${ }^{3}$ Médico Veterinário, Doutor, Professor Titular, Departamento de Veterinária (DVT), Universidade Federal de Viçosa (UFV), 36570-

000, Viçosa, MG. E-mail: ricarlo@mail.ufv.br. Autor para correspondência.

${ }^{4}$ Médico Veterinário, Doutor, Professor Adjunto, DVT, UFV.
} 
alimentados com dietas de alto valor nutritivo, são os mais acometidos por artropatias que freqüentemente evoluem para doença degenerativa (OLSSON, 1993).

A eletroterapia com campos elétricos e eletromagnéticos potencializa a reparação de tecidos conjuntivos, representando uma alternativa para auxiliar a reparação de lesões da cartilagem hialina. Sua aplicação mais amplamente pesquisada relaciona-se à reparação óssea e ocasiona a aceleração de cicatrização de fraturas recentes, não união e união óssea retardada, osteoporose e osteonecrose, bem como a incorporação de enxertos ósseos. Mais recentemente, foi descrito o efeito desses campos elétricos na reparação de cartilagem e tecidos moles. Em vários modelos experimentais e em aplicações clínicas, foi observada aceleração na síntese de matriz e na cicatrização tecidual (AARON \& CIOMBOR, 1993).

LIPPIELLO et al. (1990), ao utilizarem uma corrente elétrica pulsada, em falhas osteocondrais experimentais no fêmur distal de coelhos, observaram a formação de tecido de reparação fibrocartilaginoso ou semelhante à cartilagem hialina, com afinidade tintorial pela safranina-O, em $89 \%$ dos animais do grupo tratado. Por outro lado, nos animais do grupo não tratado, a falha foi preenchida predominantemente por tecido fibroso, sem afinidade tintorial. A osteogênese subcondral se deu por ossificação endocondral, não sendo observada diferença entre o grupo tratado e o grupo controle nesse aspecto do processo de reparação.

GRACE et al. (1998) examinaram o efeito do campo eletromagnético pulsado em falhas osteocondrais no sulco troclear de ratos. Foram observadas reação vascular inicial e supressão da proliferação inicial do tecido de granulação. A condrogênese e a formação óssea foram estimuladas, com aceleração da reconstituição de trabéculas ósseas normais. Conforme os autores o tratamento com campo eletromagnético pulsado pode ser útil na aceleração da reparação durante a fase proliferativa inicial.

AARON \& CIOMBOR (1996) estudaram o processo de ossificação endocondral, em ratos, sob influência de campo eletromagnético pulsado e observaram aceleração do tempo de reparo e aumento quantitativo na incorporação de sulfato, no conteúdo de glicosaminoglicanos e na calcificação. A estimulação das células no estádio mesenquimal do desenvolvimento ósseo endocondral foi essencial para a aceleração da formação óssea. A calcificação foi acelerada e a maturação óssea foi maior nos ossos sob estimulação. Os autores acreditam que a potencialização da diferenciação de células mesenquimais aumentou a síntese de matriz extracelular e a maturação óssea.

CANÈ et al. (1993) avaliaram, em falhas ósseas corticais realizadas em eqüinos a influência do campo eletromagnético pulsado na osteogênese, e observaram aumento na mineralização e na atividade de osteoblastos, representada pelo maior crescimento ósseo intramembranoso. Porém, não puderam determinar se o campo eletromagnético afetou também os estádios da cicatrização óssea que precedem à osteogênese.

NOGAMI et al. (1982) avaliaram, in vitro, o efeito de uma corrente elétrica contínua na condrogênese e concluíram que há inibição da diferenciação de células mesenquimais em condrócitos. Porém os autores notaram, na região do cátodo, discreta proliferação dos condrócitos préexistentes.

O presente estudo teve por objetivo avaliar, microscopicamente, os efeitos da corrente elétrica pulsada no processo de reparação de falha osteocondral, induzida no sulco troclear de coelhos.

\section{MATERIAL E MÉTODOS}

Foram utilizados 18 coelhos machos e 18 fêmeas, da raça Nova Zelândia Branca, com peso médio de $3,5 \mathrm{~kg}$ e idade entre sete e dez meses. Os animais foram mantidos em gaiolas individuais, alimentados com ração balanceada ${ }^{\mathrm{a}}$ e água $a d$ libitum.

Todos os animais receberam $40.000 \mathrm{UI} / \mathrm{kg}$ de peso corpóreo (PC) de penicilina procaína ${ }^{\mathrm{b}}$ por via intramuscular (IM), duas horas antes da cirurgia. Foram administradas 40.000UI/kg PC de penicilina benzatina $^{c}$ por via subcutânea, no pós-operatório imediato. A sedação dos animais foi obtida com cloridrato de levomepromazina ${ }^{\mathrm{d}}(2,0 \mathrm{mg} / \mathrm{kg}$ PC, IM) e a anestesia geral com a associação tiletaminazolazepam $^{\mathrm{e}}(8,0 \mathrm{mg} / \mathrm{kg} \mathrm{PC}$, via intravenosa).

A articulação fêmuro-tíbio-patelar foi acessada através de uma incisão parapatelar lateral na cápsula articular, que permitiu a luxação medial da patela e a visualização dos côndilos femurais. Por meio de osteótomo, foi criada uma falha retangular na cartilagem articular e osso subcondral do sulco troclear, de 2,0 $\mathrm{mm}$ de largura, 4,0 $\mathrm{mm}$ de comprimento e $1,5 \mathrm{~mm}$ de profundidade. A articulação foi irrigada com solução fisiológica, a patela reposicionada e a cápsula articular e pele foram suturadas, com fio de nylon em sutura contínua.

Os animais foram distribuídos em três grupos experimentais (GI, GII, e grupo controle), 
com 12 animais cada, sob os seguintes protocolos: no GI, a articulação operada foi eletroestimulada diariamente; no GII, a eletroterapia foi realizada em dias alternados; e no grupo controle, não foi realizada eletroestimulação.

A eletroterapia teve início $48 \mathrm{~h}$ após a cirurgia. As sessões tinham duração de duas horas ininterruptas ao dia e se estenderam até a data de sacrifício. O aparelho utilizado foi um eletroestimulador comercial ${ }^{\mathrm{f}}$, modificado pelo fabricante para produzir uma corrente elétrica pulsada, com forma de pulso de um pico positivo, decaindo exponencialmente. A largura do pulso empregado foi de 1,6 milisegundo, com repetição de 100 Hertz e intensidade máxima de corrente de 3,2 miliamperes.

Os eletrodos constituíam-se de discos flexíveis de borracha, sob os quais foi acoplada uma esponja umedecida em água. Este conjunto foi revestido externamente por uma capa plástica protetora. Eles eram posicionados de maneira nãoinvasiva, colocando-se o eletrodo negativo (cátodo) sobre a articulação fêmuro-tíbio-patelar e o eletrodo positivo (ânodo) sobre o dorso do animal. Eram fixados por meio de esparadrapo e tiras elásticas, diretamente sobre a pele do animal, sendo indispensável a depilação periódica das áreas de aplicação da eletroterapia para permitir o contato entre o eletrodo e a pele.

Para possibilitar a avaliação do efeito da eletroterapia em diferentes fases do processo de reparação das falhas osteocondrais, cada grupo experimental foi subdividido em três subgrupos de quatro animais, sacrificados às duas, quatro e sete semanas de pós-operatório, respectivamente. Para realização do exame microscópico, foram coletados fragmentos contendo a região da falha osteocondral, fixados em líquido de Bouin por 24 horas, descalcificados conforme indicação de LUNA (1968), desidratados, incluídos em parafina, seccionados a $5 \mu \mathrm{m}$ de espessura e corados segundo a técnica de Hematoxilina \& Eosina (GRIMALDI FILHO, 1981). Os cortes histológicos de cada falha osteocondral foram analisados ao microscópio óptico.

\section{RESULTADOS}

Às duas semanas de pós-operatório, no grupo controle e no GII, o tecido observado preenchendo a falha osteocondral tinha aspecto de tecido de granulação. Era constituído por uma rede de colágeno infiltrada por células mesenquimais, contendo vasos sangüíneos nas áreas mais profundas do tecido de reparação. A linha de fratura osteocondral estava evidente em vários pontos, onde ocorreu uma separação entre o tecido de reparação e o tecido ósseo adjacente. No fundo da falha, havia osteoclastos e osteóide, oriundo de formação intramembranosa e de ossificação endocondral (Figura 1A).

Nos animais do GI, o tecido de reparação era semelhante a tecido de granulação. Entretanto, a camada mais profunda apresentava leito vascular exuberante, constituído por vasos sangüíneos calibrosos. Havia grande número de osteoclastos e a linha de fratura estava visível somente em alguns pontos, geralmente nas regiões laterais da falha. Neste grupo, a osteogênese caracterizou-se por franca formação de osteóide no fundo e laterais da falha osteocondral, predominantemente por formação intramembranosa. Observou-se também, nos animais do GI e em um animal do GII, uma camada mais superficial bem organizada, contendo células com núcleos alongados e fibras colágenas orientadas paralelamente à superfície articular (Figura 1B). Em todos os animais do GI havia continuidade quase completa entre o tecido de reparação e o osso subcondral adjacente.

Às quatro semanas de pós-operatório, os animais do grupo controle apresentaram a falha osteocondral preenchida por cartilagem hialina, com osteogênese restrita à periferia da falha (Figura 2A). Nos GI e GII, somente as áreas do tecido de

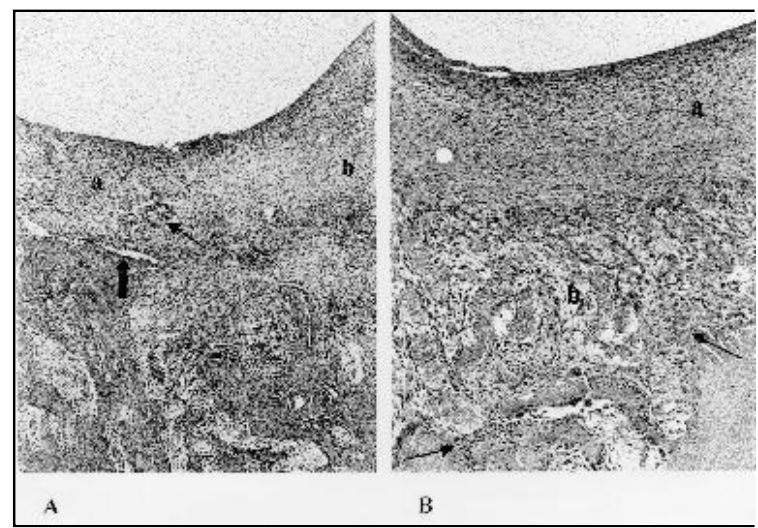

Figura 1 - Falha osteocondral, induzida em coelhos, após duas semanas de PO. A: Grupo controle. Tecido de reparação indiferenciado (a), com uma zona de diferenciação em cartilagem (b). Observar os vasos sangüíneos no tecido de reparação (seta fina). No fundo da falha, pode ser visualizada a linha de fratura, com ausência de integração e a formação de fendas (seta grossa). H \& E. 63X. B: GI. O tecido de reparação apresenta organização horizontal das fibras colágenas da camada superficial (a) e exuberante leito vascular no fundo da falha (b), na qual pode ser visualizada formação intramembranosa de osteóide (setas). H \& E. 70X. 


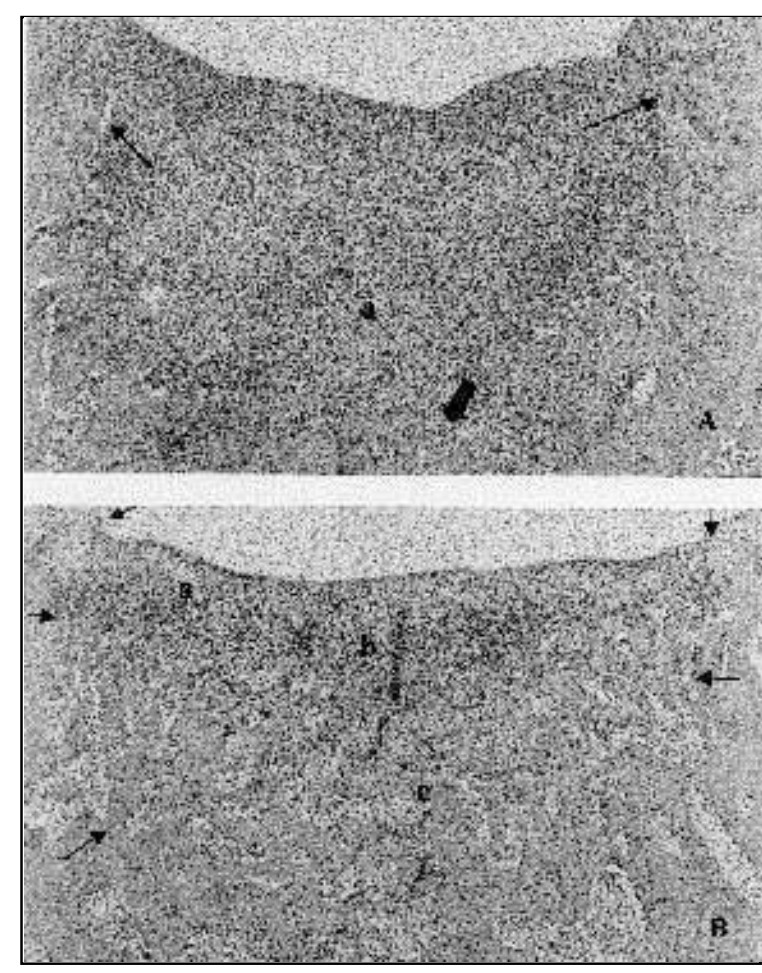

Figura 2 - Falha osteocondral, induzida em coelhos, após quatro semanas de PO. A: animal do grupo controle com preenchimento da falha por cartilagem hialina. Há integração (seta larga) do tecido de reparação (a) ao osso sudjacente (b). Podem ser visualizadas a linha de fratura e fendas (setas finas). $\mathrm{H} \&$ E. 63X. B: animal do GI. Observa-se tecido de reparação indiferenciado (a) e cartilagem hialina (b). No fundo da falha verifica-se osso novo (c). O tecido de reparação encontra-se integrado à cartilagem remanescente e ao osso adjacente (setas). H \& E. 63X.

reparação próximas ao tecido ósseo apresentavam diferenciação em cartilagem, geralmente com condrócitos hipertrofiados. Superficialmente a esta região de aspecto hialino, havia áreas de fibrocartilagem e áreas onde as células tinham núcleos alongados ou triangulares, com aspecto semelhante a células mesenquimais indiferenciadas. Subjacente ao tecido de aspecto cartilaginoso, observou-se osteogênese por ossificação endocondral, com formação de osso trabecular bem vascularizado e regeneração parcial do osso subcondral excisado (Figura 2B).

Às sete semanas, os animais do grupo controle e dois do GII apresentaram as falhas preenchidas predominantemente por cartilagem hialina, com algumas áreas de fibrocartilagem. Foram observados vacúolos de diferentes tamanhos na camada mais superficial do tecido de reparação em dois animais do grupo controle e em um do GII.
Houve integração com o tecido ósseo subjacente, embora em alguns pontos, onde a linha de fratura ainda estava presente, ocorreu a separação entre o tecido de reparação e o tecido ósseo adjacente. A regeneração do osso subcondral excisado era parcial, abaixo da linha da junção osteocondral preexistente (Figura 3A).

Nas falhas osteocondrais dos animais do GI e de dois animais do GII, observou-se, superficialmente, uma camada de tecido indiferenciado, acima de uma camada de cartilagem hialina. Foram observados condrócitos hipertrofiados e matriz extracelular basófila adjacentes ao osteóide, participando da seqüência de ossificação endocondral. O fundo da falha encontrava-se preenchido por osso novo esponjoso, até a linha da junção osteocondral preexistente, havendo integração completa do tecido de reparação com a falha osteocondral produzida (Figura 3B).

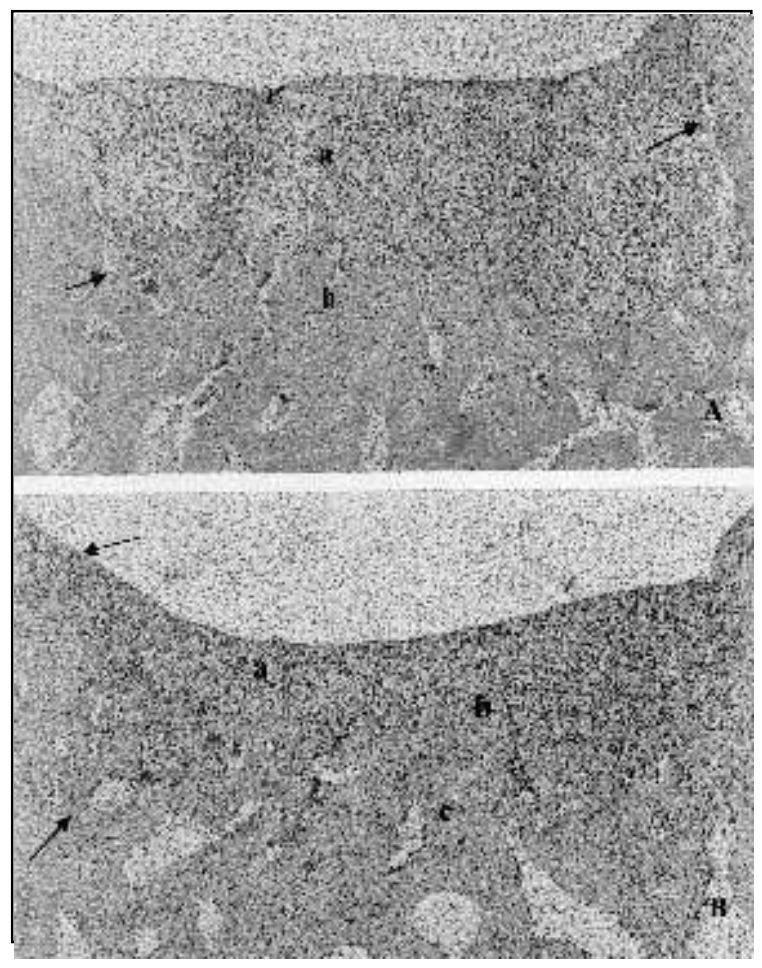

Figura 3 - Falha osteocondral, induzida em coelhos, após sete semanas de PO. A: animal do grupo controle. Observa-se cartilagem hialina (a) e osso novo no fundo da falha (b). Há fendas entre o tecido de reparação e o tecido ósseo adjacente (setas). H \& E. 63X. B: animal do GI. Tecido indiferenciado superficialmente (a), com aspecto de cartilagem hialina (b) junto ao osso novo (c) que preenche o fundo da falha. Há integração entre o tecido de reparação e a cartilagem e tecido ósseo adjacentes (setas). H \& E. 63X. 


\section{DISCUSSÃO}

A neovascularização abundante observada às duas semanas de pós-operatório nos animais do GI deveu-se à eletroestimulação diária, sendo também descrita por GRACE et al. (1998), como resultado da estimulação por campo eletromagnético pulsado. A maior vascularização desencadeada pelo estímulo elétrico pode explicar a cicatrização mais rápida observada em diversos modelos experimentais que empregaram a eletroterapia (AARON \& CIOMBOR, 1993).

$\mathrm{O}$ tecido indiferenciado observado em todos os animais do GI e dois do GII, até sete semanas de pós-operatório, sugere que a eletroestimulação, com a corrente elétrica pulsada empregada nesta pesquisa, impediu que a diferenciação tecidual em cartilagem hialina ocorresse de maneira uniforme, em toda a extensão do tecido de reparação, como foi verificado nos animais do grupo controle. Também foi observado, in vitro, por NOGAMI et al. (1982) a inibição da diferenciação de células mesenquimais em condrócitos em decorrência do estímulo elétrico, mas os autores não sugeriram o possível mecanismo.

LIPPIELLO et al. (1990) observaram a formação de cartilagem hialina em $89 \%$ dos animais eletroestimulados. Entretanto, os autores referem que estes animais foram mantidos, em observação, por um período adicional de 6 a 24 semanas, sem que fosse realizada a eletroterapia. Eles inferem que a diferenciação em cartilagem possa ter ocorrido após o término da eletroterapia.

Somente um animal do grupo estimulado em dias alternados (GII) apresentou vascularização abundante como no GI, demonstrando que a aplicação da corrente elétrica utilizada no presente trabalho, a cada 48h, não foi capaz de induzir angiogênese na mesma intensidade observada nos animais estimulados diariamente. Os animais do GII apresentaram características intermediárias entre o grupo controle e o GI, sugerindo que os efeitos da eletroestimulação, referentes a angiogênese, são dependentes do tempo sob estimulação.

A camada mais superficial rica em fibras colágenas, dispostas paralelamente à superfície articular, observada às duas semanas de pósoperatório em todos os animais do GI e alguns do GII, sugere que a eletroestimulação induziu o aumento na atividade de síntese de colágeno pelas células presentes no tecido de reparação. Outros autores também observaram aumento na síntese de matriz extracelular em decorrência do estímulo elétrico (AARON \& CIOMBOR, 1993).
A reposição do osso subcondral foi realizada predominantemente por ossificação endocondral. Admite-se que a eletroestimulação acelerou e intensificou o processo de ossificação endocondral, proporcionando maior osteogênese nos animais do GI e em $30 \%$ do GII. Isto confirma os achados de outros autores que também observaram potencialização da ossificação endocondral em decorrência de estímulo elétrico (AARON \& CIOMBOR, 1993). AARON \& CIOMBOR (1996) afirmaram que a estimulação do tecido ainda indiferenciado é essencial para que ocorra aceleração da ossificação endocondral. Sugerem ainda que o campo eletromagnético module mecanismos de membrana, mediados por receptores de citocinas relacionadas com a diferenciação celular, alterando o processo de tradução dos sinais de estímulos regulatórios e, assim, influenciando a regulação de atividades celulares de transcrição e síntese.

Às duas semanas de pós-operatório, podese observar formação intramembranosa de osteóide no fundo e laterais das falhas em todos os animais experimentais. Contudo, a ossificação mais intensa verificada nos animais do GI, com maior número de osteoblastos na superfície das trabéculas ósseas e maior produção de osteóide do que nos animais do grupo controle, demonstrou que a eletroestimulação intensificou também a formação intramembranosa de osteóide, o que está de acordo com as observações de CANÈ $\boldsymbol{e t}$ al. (1993).

Os vacúolos observados em animais dos grupos II e controle são sugestivos de lesões degenerativas da cartilagem de reparação. Nos animais do GI e do GII em que a osteogênese encontrava-se mais avançada, não foram observados vacúolos na superfície do tecido de reparação, sugerindo que a reconstituição precoce do leito ósseo subcondral preveniu o desenvolvimento de lesões degenerativas na cartilagem de reparação. SHAPIRO et al. (1993) relataram que somente em um pequeno número de animais, em que o osso subcondral havia sido reconstituído, a cartilagem de reparação não apresentava as alterações degenerativas observadas na maioria das falhas com 24 semanas de pós-operatório. Os autores sugeriram que a manutenção da integridade da cartilagem articular de reparação depende da reconstituição do tecido ósseo excisado. Assim, acredita-se que a potencialização da osteogênese proporcionada pelo estímulo elétrico possa, nesse aspecto, pode beneficiar o processo de reparação de falhas osteocondrais.

Apesar de os animais do GI apresentarem regeneração completa do osso subcondral removido 
na curetagem da superfície articular, não foi observada a sua remodelação em osso lamelar compacto, provavelmente porque a reparação foi avaliada somente até a sétima semana. Esse é um processo progressivo e normalmente demorado, conforme verificaram SHAPIRO et al. (1993), ao observarem a reorganização da arquitetura do osso subcondral após 24 semanas de pós-operatório.

Ainda, pôde-se verificar que os animais do GI apresentaram melhor integração entre o tecido de reparação e o tecido ósseo adjacente que os animais dos grupos II e controle, nos três tempos pós-operatórios. Isto ocorreu devido à abundante vascularização e à intensificação dos processos de ossificação endocondral e de remodelação óssea.

\section{CONCLUSÕES}

Com base nos resultados desta pesquisa, pode-se concluir que o estímulo elétrico aplicado na superfície articular lesada de coelhos, impede que a diferenciação tecidual em cartilagem hialina ocorra de maneira uniforme, em todo o tecido de reparação. Por outro lado, a ossificação endocondral é acelerada, ocorrendo regeneração do osso subcondral, até o nível da junção osteocondral preexistente, em coelhos eletroestimulados durante sete semanas. A eletroterapia pós-operatória, nas fases iniciais (4 semanas) proporciona também melhor integração entre os tecidos de reparação e o remanescente no fundo da falha osteocondral, produzida em coelhos, nas dimensões descritas.

\section{FONTES DE AQUISIÇÃO}

a. Ração Coelhil "R", Socil, Belo Horizonte.

b. Despacilina, Bristol-Meyers Squibb, São Paulo.

c. Penicilina G. benzatina, Eurofarma, São Paulo.

d. Neozine, Rhodia, São Paulo.

e. Zoletil 50, Virbac, São Paulo.

f. Eletroestimulador FGS Plus, KW Eletrônica LTDA, Paulínia, SP.

\section{REFERÊNCIAS BIBLIOGRÁFICAS}

AARON R.K., CIOMBOR D.M. Therapeutic effects of eletromagnetic fields in the stimulation of connective tissue repair. Journal of Cellular Biochemistry, v.52, n.1, p.4246, 1993.

AARON R.K., CIOMBOR, D.M. Acceleration of experimental endochondral ossification by biophysical stimulation of the progenitor cell pool. Journal of Orthopaedic Research, v.14, p.582-589, 1996.

CANÈ, V., BOTTI, P., SOANA, S. Pulsed magnetic fields improve osteoblast activity during the repair of an experimental osseous defect. Journal of Orthopaedic Research, v.11, n.5, p.664-670, 1993.

GRACE, K.L., REVELL, W.J., BROOKES, M. The effects of pulsed electromagnetism on fresh fracture healing: osteochondral repair in the rat femoral groove. Orthopedics, v.21, n.3, p.297-302, 1998.

GRIMALDI FILHO, G. Manual de técnica histológica. Rio de Janeiro : Instituto Oswaldo Cruz, 1981. 287p.

LIPPIELLO, L., CHAKKALAKAL, D., CONNOLLY, J.F. Pulsing direct current-induced repair of articular cartilage in rabbit osteochondral defects. Journal of Orthopaedic Research, v.8, n.2, p.266-275, 1990.

LUNA, L.G. Manual of histologic staining methods of the armed forces institute of pathology. 3 ed. New York : Mc Graw-Hill Book, 1968. 258p.

NOGAMI, H., AOKI, H., OKAGAWA, T., et al. Effects of eletric current on chondrogenesis in vitro. Clinical Orthopaedics and Related Research, n.163, p.243-247, 1982.

OLSSON, S. Pathophysiology, morphology, and clinical signs of osteochondrosis in the dog. In: BOJRAB, M.J. Disease mechanisms in small animal surgery. 2 ed. Philadelfia : Lea \& Febiger, 1993. Cap.111, p.777-796.

SHAPIRO, F., KOIDE, S., GLIMCHER, M.J. Cell origin and differentiation in the repair of full-thickness defects of articular cartilage. The Journal of Bone and Joint Surgery, v.75 A, n.4, p.532-553, 1993.

Ciência Rural, v. 31, n. 5, 2001. 